\title{
Práticas agrícolas de conseqüências genéticas que possibilitaram aos índios da Amazônia uma melhor adaptação às condiçōes ecológicas da região
}

\author{
Warwick Estevam Kerr $\left({ }^{*}\right)$ \\ Charles R. Clement $(* *)$
}

\section{Resumo}

Os cultivares de plantas, de valor alimentício, encontrados na Amazônia, diferentes da população selvagem encontrada nas matas, foram selecionados pelos indios nos últimos 10.000 anos, para a América do Sul inteira e, possivelmente, nos últimos 4000 a 1000 anos para as plantas domesticadas na Amazônia. Este trabatho analisa 40 cultivares de mandiocas e macaxeiras dos Desâna e 13 dos Tikúna. Contagens em 7 tribos revelaram uma média de 22 cultivares por tribo. Indicase para as fruteiras: abiu, sapota, sapoti, pupunha, abacaxi, o tamanho e características das plantas selvagens e das selecionadas pelos índios. Mencionam-se, também, algumas tuberosas (cará, batata-doce, taioba, ariá, caroço-de-umari) domesticadas e o cupá (Cissus gongilodes); este último talvez seja uma das domesticações mais recentes. Sugere-se que o pato (Cairina moschata) se tenha autodomesticado, por meio de poucas mutaçōes, com o que ocuparia um nicho ecológico vazio.

\section{INTRODUÇÃo}

É incorreto dizer que todos os índios põem em prática medidas preservadoras da natureza e vivem em bom equilíbrio com ela. Por exemplo, os Cintas-Largas e os Yanomamö por pouca dificuldade que tenham em subir numa árvore, põe-na abaixo, para coletar os frutos. Os Cintas-Largas fizeram isto até com o ingazeiro do Núcleo Pioneiro de Humboldt, em Aripuanã!

Por outro lado, já se conhecem várias práticas, com conseqüências genéticas, dos índios Inca e Aymará, no processo de plantio e colheita do milho. Brieger (com. pessoal) afirma que os sacerdotes Inca colhiam no campo as melhores espigas, cujos grãos serviriam de sementes para a próxima geração. Afirma, também, que os Guaraní não misturavam variedades de milho plantando-as em épocas diferentes, de modo que o pólen de uma variedade não contaminasse outra.
Não temos dúvida de que técnicas de cultivo e variedades melhoradas de frutas, raízes, legumes, cereais contribuiram no passado (e ainda contribuem nos dias de hoje) para que uma população tenha maior independência do ambiente (homeostasia) e, conseqüentemente, maior estabilidade.

Ao referirmo-nos aos "Índios da Amazônia" devemes deixar logo claro que existem dezenas de nações, cada uma com língua, religião, costumes e tradições próprias. Neste trabaIho, vamos referir-nos a algumas práticas agrícolas e a algumas piantas de umas poucas tribos de índios agricultores com as quais tivemos contato direto: Tikúna (a maior tribo brasileira do momento). Paumarí, Yamamadí, Cinta-Larga, Desâna, Tukána, Galibí, Paiikúr e Kayapó.

MANUtenção DA HETEROGENEIDAdE GENÉtica NA NATUREZA

As plantas na Amazônia têm alta freqüência (mais de $50 \%$ ) de espécies de fecundação cruzada obrigatória (dióicas ou com mecanismos de autoesterilidade, inclusive monóicas) indicando a grande importância de se produzir uma enorme quantidade de genótipos para ocupar, em competição inter e intra específica, um grande número de nichos ecológicos (Kerr, 1978). Ao lado desse mecanismo diversificador e inovador, existe um altamente conservador: a reprodução vegetativa, por meio de rizomas (ariá), brotamento do caule (pau-rosa, pupunha, açai) brotamento das raízes (araçápeua, bacuri e muitas espécies), brotamento de manivas (mandioca, cupá), bulbos. Essa aliança dá às plantas o máximo de preservação

(") - Novo endereço: Departamento de Genética, Faculdade de Medicina de Ribeirão Preto, 14.100. SP

${ }^{(* *)}$ - Instituto Nacional de Pesquisas da Amazônia, Manaus. 
da espécie: por meio de sementes, distribuindo amplamente milhares de combinação gênicas diferentes por ano e, vegetativamente, reproduzindo a própria planta no mesmo local em que o genótipo antigo foi bem sucedido.

Simões (1972) relata algumas datações de Carbono-14 para cerâmicas da Amazônia. As mais antigas vão de 1500 anos atrás quase nos limites do Brasil com Peru e Colômbia, 1550 em Manacapuru, 1400 em Manaus, e 3000 em Marajó.

Para cozer mandioca, milho, jerimum, cará, favas, taioba, etc... os índios necessitam de vasilhames de barro. Assim, o advento da ce. râmica é uma boa indicação de que os índios já haviam domesticado algumas plantas. O número de variedades (que dependem de mutação e, portanto, quanto mais tempo, maior probabilidade de ocorrência), a gradual distribuição em tribos diferentes (que depende de contatos pacíficos ou bélicos) e a maior ocupação de área geográfica são também fatores indicativos da maior ou menor antigüidade da domesticação de uma espécie.

Assim, uma espécie como a mandioca, o jerimum, o abacaxi, o cará, a batata-doce, o milho, de uso em dezenas de tribos, muitas variedades, grande área de distribuição, devem ter mais de 4.000 anos (4 a 10 mil anos). Aquelas como o cupá, a sapota, o mapati, o feijão-macuco, apenas conhecidos em poucas tribos, devem ter domesticação recente $(1.000$ a 2.000 anos?), e outras seriam intermediárias, como a pupunha, ariá, cacau, bananeira, amendoim, etc. (2000 a 4000 anos) .

As plantas mais antigas dos índios sulamericanos, possivelmente, são: milho, mandioca e jerimum. As três são monóicas e os índios têm delas um enorme número de cultivares. Sobre o milho há relatos de datação, de seu pólen, de 60.000 anos (literatura em Goodman \& Smith, 1978) que cremos tratar-se da forma selvagem. Whitaker (1976) cita as abóboras, morangas, jerimuns, como existentes na América do Sul, há mais de 10.000 anos. Jennings (1976) diz que a mandioca é uma das primeiras plantas domesticadas pelos índios na Amazônia, talvez há 4.000 ou 5.000 anos atrás. O maior númerc de cultivares que encontramos, por tribo, foi em mandioca, dado o fato de os índios terem nessa espécie um perfeito controle da reprodução assexuada. Nas roças dos Yamamadí, Paumarí, Tikúna, Desâna e Galibí, verificamos que cada variedace é plantada na quantidade desejada em terrenos separados por troncos de árvores. Não obstante tais mandiocas terem canteiros separados, elas participam, na floração, de um mesmo conjuntơ gênico e, conseqüentemente, há produção de novo zigoto em cada semente produzida. Goodman \& Smith (1978: 52), para o milho, citam 250 raças para a América Latina, todos descendentes do material deixado pelos indios. Zevallos et al. (1977) demonstraram que já existiam duas variedades de milho, numa povoação primitiva do Equador (Valdivia V-VI), estudando baixos relevos de milho nos potes de cerâmica feitos com os próprios grãos, e datados de 4.900 anos atrás, e um sabugo que foi datado de 3.980 anos atrás.

\section{DADOS SOBRE ALGUMAS PLANTAS INDÍGENAS CULTIVADAS}

Para ter-se uma idéia sobre uma parte do conhecimento dos índios Tikúna, de vários alimentos, veja a Tabela 1, com informações obtidas por Danilo F. Silva Filho no dia 04-12-79, em Arara (Colômbia), vila Ticuna com 60 casas, distante $24 \mathrm{~km}$ NO de Letícia. O companheiro informante foi o índio Modestino Miguel. de 65 anos.

Vamos apresentar, neste trabalho, dados sobre as seguintes plantas: mandioca, fruteiras, tuberosas e cupá.

\section{MANDIOCA}

Os índios amazônicos obtem suas proteínas com facilidade por meio da caça e da pesca e suas vitaminas das frutas. Uma grande invenção de tecnologia alimentar foi a fabricação de farinha de mandioca. Na região entre Iquitos (Peru) e Belém (Pará), porém com um pouco de difusão nos afluentes, uma nova invenção foi feita: a do tipiti. O tipiti permite uma rápida separação do tucupi da massa da 
TABELA 1 - Conhecimento de vários alimentos pelos índios Tikúna, residentes em Arara, Colômbia (25 km NO de Tabatinga, AM.). Todas as frutas mencionadas são consumidas normaimente como alimento; nenhuma é remédio.

\begin{tabular}{|c|c|c|c|c|c|}
\hline Nome Brasileiro & $\begin{array}{c}\mathrm{N} .^{\circ} \text { de } \\
\text { Cultivares }\end{array}$ & Nome Tikúna & Nome Brasileiro & $\begin{array}{c}\mathrm{N} .^{\circ} \text { de } \\
\text { Cultivares }\end{array}$ & Nome Tikúna \\
\hline Abacate & $2 *(7)$ & Goumã & Cupá & 0 & - (năo conhecem) \\
\hline Abacaxî & 4 & Tiẽnã & Cupuaçu & 1 & Kôpú \\
\hline Abiu & 2 & Taú & Fruta-päo & $1 *(5)$ & Päotchane \\
\hline Açai & $3^{*}(6)$ & Uaira & Goiaba & 4 & Oratchá \\
\hline Apuruí & 0 & - (não conhecem) & Graviola & 1 & Djaca \\
\hline Araçá-boi & 0 & - (não conhecem) & Ingá chinelo & 1 " $(2)$ & Tôú \\
\hline Araçá-goiaba & 1 & Taué & Ingá cipó & 1 & Ingauaçú \\
\hline Araçá-peba & 0 & - (não conhecem) & Inhame & 0 & - (näo conhecem) \\
\hline Ariá & 1 & Eirú & Jaca & $1^{\circ}(5)$ & Jaca \\
\hline Bacaba & 1 & Borôá & Jerimum & 2 & Jurumum \\
\hline Bacuri (grande) & 1 & Kói & Macaxeira & 5 & Têé \\
\hline Bacuri (pari) & 1 & Pókuri & Mandioca & $5 *(9)$ & Moneka ou Óua \\
\hline Banana & 9 & Póí & Mapati & $2^{\circ}(2)$ & Tiêã \\
\hline Batata-doce & $3^{*}(3)$ & Coré & Milho & 1 & Tchaú \\
\hline Biribá & $2^{*}(1)$ & Vêriuá & Murici & 0 & - (não conheceni) \\
\hline Buriti & 1 & $\begin{array}{l}\text { Veriua } \\
\text { Temā }\end{array}$ & Pajurá & 0 & - (não conhecem) \\
\hline Cacau & 2 & Tchaperé & Patauá & 1 & Die \\
\hline Caju & 1 & $\begin{array}{l}\text { Tchapere } \\
\text { Kóú }\end{array}$ & Pupunha & $2{ }^{*}(1)$ & Entú \\
\hline Cará & $2 "(4)$ & $\begin{array}{l}\text { Kóú } \\
\text { Òi }\end{array}$ & Sapota & 1 & Óteré \\
\hline Castanha-do-pará & 1 & $\begin{array}{l}\text { Oi } \\
\text { Katãia }\end{array}$ & Sapotilha & 0 & - (não conhecem) \\
\hline Coco-da-bahia & $1 *(5)$ & $\begin{array}{l}\text { Katăia } \\
\text { Koko }\end{array}$ & Taioba & 1 & Nō \\
\hline & $1(0)$ & Koko & Taperebá & $2{ }^{*}(8)$ & Djaumêru \\
\hline
\end{tabular}

-(1) - Tanto de pupunha como de biribá existe uma va-riedade silvestre no mato.

* (2) - Em toda a Amazónia, existe matapi nâo domesticado. silvestre, de frutos pequenos. Já o ingá chinelo, tanto o silvestre como o cultivado sāo iguais. Os indios Tikúna reconhecem 2 variedades : roxo e verde.

(3) - 3, Cultivares: branca, amarela e roxa.

(4) - Branco e roxo.

*(5) - Introduçấo relativamente recente.

* (6) - Podem ser 3 espécies: uma é roxa, outra preta e outra cinza.

(7) - Abacate verde, abacate roxo.

( $(8)$ - Um laranja e um vermelho.

(9) - Os Tíkúna têm farinha d'água (Óigaein), farinha seca (Ótica) e usam o tipiti (Tipiti) e tucupi (Tucupi).

farinha a ser secada (e, ao mesmo tempo, verse livre do HCN). Há dois tipos básicos de farinha: seca e d'água. Maravalhas (1964), Marinho et al. (1978), Giugliano et al. (1978) e Shrimpton \& Giugliano (1979) informam que o amarelo da mandioca é dado por provitamina A e que a farinha d'água mantém mais a vitamina $A$ que a seca.

Até hoje, nas tribos "mandioqueiras" que visitamos, encontramos, em ordem decrescente, o seguinte número de cultivares: 40 cultivares nos Desâna (os Tukána, estudados por Bertha Ribeiro, cevem ter algumas a mais, pois ocupam território bem maior), 17 nos Yamamadí, 14 nos Palikúr, 14 nos Galibí, 14 nos Tikúna (estivemos em apenas uma aldeia Tikúna Umarí-açu - suspeitamos existir pelo menos o dobro nessa grande tribo - a maior da amazônia) e 12 nos Paumarí (suspeitamos que haja aqui o mesmo número que em Yamamadí). Grosseiramente temos aqui (supondo, neste cálculo, os Tukána com igual número que os Desâna) uma média de 22 variedades por aldeia de índios.

O índio Sabá, líder de uma aldeia Yamamadí informou-nos que, durante a vida dele, nunca passou um dia sem mandioca ou macaxeira: umas variedades são boas para várzea, outras para terra firme, umas dão em 5-6 meses, outras em um ano e, informaram-nos os Paumarí, 
outras se agüentam sob a terra até por 5 anos (não cremos neste dado, porém significa que permanecem boas para consumo por um a três anos) .

Segundo Ribeiro (1955), os índios UrubusKaapor cultivam 28 piantas diferentes, porém $80 \%$ da área de seus roçados são destinados à mandioca, que constitui a base da alimentação. Suas roças são excepcionalmente importantes de maio a agosto, quando dependem delas por estarem ilhados pelas enchentes. Relaciona para os Urubus 9 cultivares, sendo 8 de mandiocas e um de macaxeira. Vamos a seguir (Tabela 2), citar os 40 cultivares de mandioca dos índios Desâna, do alto rio Negro, por informações que obtivemos do nosso amigo (hóspede do INPA por 3 meses) Tolamen Ken-híri, chefe dos Desâna (com carteira de identidade e CPF sob o nome brasileiro de Luiz Gomes Lana), inclusive com a descrição sumária de cada um. (')

Daremos na Tabela 3 os cultivares encontrados em apenas uma aldeia dos Tikúna (de Umari-açu, em Tabatinga, alto rio Solimões, fronteira com Colômbia e Peru), por informações dadas em 26.02.79 pelo índio Tikúna Sr. Camilo Mestança, de 51 anos, perante 4 índios de sua aldeia que assentiam, comentavam ou acertavam suas informações :

O que queremos demonstrar com estas informações é que, aproveitando-se da variabilidade genética, os índios amazônicos conseguiram vencer e usar a variabilidade ecológica (terra firme, várzea, tempos de seca relativa, tempos de chuvarada, fortemente ensolarada, pouco ensolarada, etc.).

\section{FRUTEIRAS}

A quantidade de frutas úteis à alimentação humana, na Amazônia, é enorme. Frei Gaspar de Carvajal (1543) relata a grande quantidade de fruteiras plantadas nas aldeias indígenas. Como tradição (ou religião) os índios afirmam que, uma fruta grande e/ou gostosa é presente de Deus e, como tal, necessita ser preservada (plantando suas sementes) e compartilhada dando-as a seus amigos que, por sua vez, precisam plantá-las. A virtude da compartilhação vai ao ponto de os Tikúna terem campos comuns de plantio (Téllez, 1979) e de os Cintas-Largas tirarem uma comida gostosa da boca para repartirem com o companheiro ou amigo (Marcos dos Santos, (com. pessoal) . Por centenas de anos, os Tikúna (Rio Solimões), Tukána (Rio Negro) e tribos sob suas influências selecionaram fruteiras com grande eficiência mantendo, inclusive, variedades distintas de várias espécies, como de bananeiras, de abiu, de pupunha. As fruteiras mais comumente encontradas nas tribos da Amazônia Ocidental que tem agricultura são: bananeiras (Musa x paradisiaca L.), Castanheira (Bertholletia excelsa Humb. et Bompl.), abiu (Pouteria caimito (Ruiz e Pav.) Radlk., Sapotaceae), sapoti (Manilkara zapota (L.) P. van Royen, Sapo. taceae) graviola (Annona muricata L., Annonaceae), pupunha (Bactris gasipaes HBK, Palmae)), biribá (Rollinia mucosa (Jacq.) Baill., Annonaceae), mapati, cucura ou purumã (Pourouma cecropiaefolia Mart., Moraceae), sapota (Quararibea cordata (Humb. \& Bonpl.) Vischer, Bombacaceae (abacaxi (Ananas comosus L.) Merril, Bromeliaceae), goiaba (Psidium guajava L.) Raddl., Myrtaceae), araçá-peba (Psidium arboreum, Vell., Myrtaceae), araçá-goiaba (Psidium acutangulum D.C., Myrtaceae), Ingá (Inga edulis Mart. e Inga cinnamomea Benth., Leguminosae), caju (Anarcadium occidentale L., Anacardiaceae), cacau (Theobroma cacau, Sterculiaceae), cupuaçu (Theobroma grandiflorum (Willd. ex Spreng), Schum., Sterculiaceae). Carvajai et al. (1543) diz encontrar nas aldeias: bananeiras, biribá, goiaba, abiu, castanha, pupunha, batata-doce, ariá, cará, mandioca e macaxeira.

As seleções mais impressionantes feitas pelos índios nas fruteiras da Amazônia são: Abiu (Pouteria caimito): A variedade selvagem (ainda encontrada nas matas) possui frutos que pesam cerca de 30 gramas. No alto Soli-

(1) - A Dra. Bertha Ribeiro vem estudando esta área e coletou informações com a esposa (que é Tukána) do Sr. Tolamen, que são parecidas com as nossas. A tabela 2, após estar pronta, foi remetida para o Sr. Tolamen que teve tempo de corrigi-la e completá-la com seus companheiros. 
TABELA 2 - Mandioca (Manihot esculenta Crantz) : cultivares encontrados entre os Desâna e sua descrição sumária.

Português ou Língua-Geral

A. Mandiocas amarelas :

01. mandioca preta
02. mandioca de macaco
03. samaúma
04. ovo de tartaruga
05. mandioca de gato
06. mandioca de tucunaré
07. mandioca de flores
08. mandioca de pacu
09. mandioca de cucura
10. mandioca de muriti
11. mandioca de paca
12. mandioca de milho
13. mandioca abiu
14. mandioca ovo de pacu
15. mandioca de abacaxi
16. mandion

B. Mandiocas brancas :

01. mandioca de conori (frutinha do mato)
02. mandioca da fruta-do-conori
03. mandioca de bacaba
04. mandioca gato-branco
05. mandioca de rã
06. mandioca rainha de mandivara
07. mandioca de tucunaré branco
08. mandioca da folha de banana
09. mandioca de mandivara
10. mandioca de abacate
11. mandioca baixota
12. mandioca caba
13. mandioca tatu
14. mandioca beiju pequeno
15. mandioca papagaio
16. mandioca de calango
17. mandioca de ingá
18. mandioca estrume de abelha
19. mandioca nâo-tem-pai
20. -
21. Landioca dos Maku
22. m.
23. mana

niirím-dk
gaki-dk
poá-dk
peiudieri-dk
piissana-dk
bu-dk
goli-dk
uhu-dk
eguí-dk
né-dk
semé-dk
hodka-dk
duabê-dk
caalé-dk
ohodire-dk
serā-dk

uassôp-dk
uassôp-seri-dk
nhumú-dk
pissana-dk boréri
omá-dk
mengã dialã-dk
boo-dk-boréri
ohopôli-dk
mengä-dk
uñu-dk
(veio de Manaus)
uti-dk
pamó-dk
ala-polä-dk
wékó-dk
alãnha-dk
merẽ-dk
momé guëla-dékè
pahque-marili-dk
vara-dk
coló-dk
pali-dk
churimã-dk

\section{Descrição}

C. Macaxeira - só uma variedade, branca.

TOTAL: 40 cultivares

LEGENDA :

$a=$ alta; $m=$ altura média; $b=$ baixa.

1 o 6 - indicam a cor da raiz da mandioca em tonalidades de amarelo, desde o amarelo forte quase gema, até o amarelo creme.

1 - fortemente amarelo, meio gema de ovo; 2 - amarelo bem forte; 3 - amarelo forts; 4 - amarelo; 5 - amarelado; 6

- creme.

AP $=$ alta produçăo

$\mathrm{fb}=$ folha vermelha e flor branca

$\mathrm{fr}=$ folho e flor vermelha

$\mathrm{fv}=$ folha verde e flor creme

pe $=$ peciolo escuro, quase preto

$p=$ precoce (ao redor de 6 meses)

$t=\operatorname{tardia~(~} 1$ ano ou mais)

Dékề ou $\mathrm{dk}=$ mandioca no lingua Desâno.

2, fv, m, p, AP

5, fv, m; t

$6, \mathrm{fv}, \mathrm{a}, \mathrm{t}$

5. fr, a, p, AP

4, fv, a, p

6 , fr, pe, a, t

$3, \mathrm{fr}, \mathrm{m}, \mathrm{t}, \mathrm{AP}$

6. $\mathrm{fr}, \mathrm{m}, \mathrm{p}$

5. fv, pe, a, t, AP

2, fv, m, t

6. fv, a, p

$3, f v, a, t, A P$

$6, f v, a, t$

3, fv, m, t, AP

6, fv, b. p

1. $f v, m, t, A P$
a, p. AP
a, $t$
$m, p, A P$
a, $p$,
$m, t, A P$
a, AP
$\mathrm{fb}, \mathrm{a}$
b. $A P$
$\mathrm{m}, \mathrm{t}$
a, $p$
b, $p, A P$
a, p, AP
a, p, AP
$m, t$
a, $p, A P$
$m, p, A P$
a, $t$
$m, t, A P$
$P$

fv, $p$ 
TABELA 3 - Cultivares de mandioca dos Tikúna.

\begin{tabular}{lll}
\hline & Português & \multicolumn{1}{c}{ Tikúna } \\
\hline $\begin{array}{l}\text { 1. MANDIOCAS } \\
\text { a) Amarelas }\end{array}$ & de jabuti & $\begin{array}{l}\text { parauá(") } \\
\text { ichá(") } \\
\text { yoo-bë( (") } \\
\text { muna(creme) } \\
\text { no-hu }\end{array}$ \\
2. MACAXEIRAS & arara & $\begin{array}{l}\text { a-um } \\
\text { a) Amarelas }\end{array}$ \\
jacamim & peixe-boi & $\begin{array}{l}\text { airué } \\
\text { vituria }\end{array}$ \\
b) Brancas & - & $\begin{array}{l}\text { pe-é } \\
\text { boré } \\
\text { aruanã }\end{array}$ \\
béga \\
uá-paraná
\end{tabular}

LEGENDA: $(*)=$ muito amarelas.

mões, (Benjamin Constant a Fonte Boa) os indios selecionaram variedades que alcançaram até $1800 \mathrm{gr}$ por fruto. Todavia, como as árvores que tinham tais frutos alcançaram pequena produção, optamos (no início seguindo o conselho dos Tikúna e mais tarde dos colegas Charles Clement e Danilo Silva Filho) por frutos ao redor de $1000 \mathrm{gr}$ e, em 1978, um dos nossos técnicos (Danilo) trouxe $13 \mathrm{~kg}$ de sementes de frutos, que pesavam cerca de $1 \mathrm{~kg}$ cada (Figura 1). Vale lembrar que o abiu possui flores unissexuais e hermafroditas. Em Ribeirão Preto tive, por alguns anos, uma árvore que floria intensamente, porém sendo isolada, não produzia frutos, revelando autoesterilidade, o que é comum pelo menos em algumas plantas. Os Desâna reconhecem 3 variedades: abiu papagaic (os grandes), abiu verde e abiu amarelo.

Mapati, purumã, cucura, uvilha (Pourouma cecropiaefolia): É uma árvore bastante semeIhante às embaúbas exceto quanto às infrutescências, que parecem um cacho de uva. Em Manaus e Aripuanã, encontramos as variedades nativas, selvagens, pequenas, de caroço grande, pouco produtivas. Os indios Tikúna melhoraram consideravelmente essa espécie; nos arredores de Letícia (alto Solimões) estão

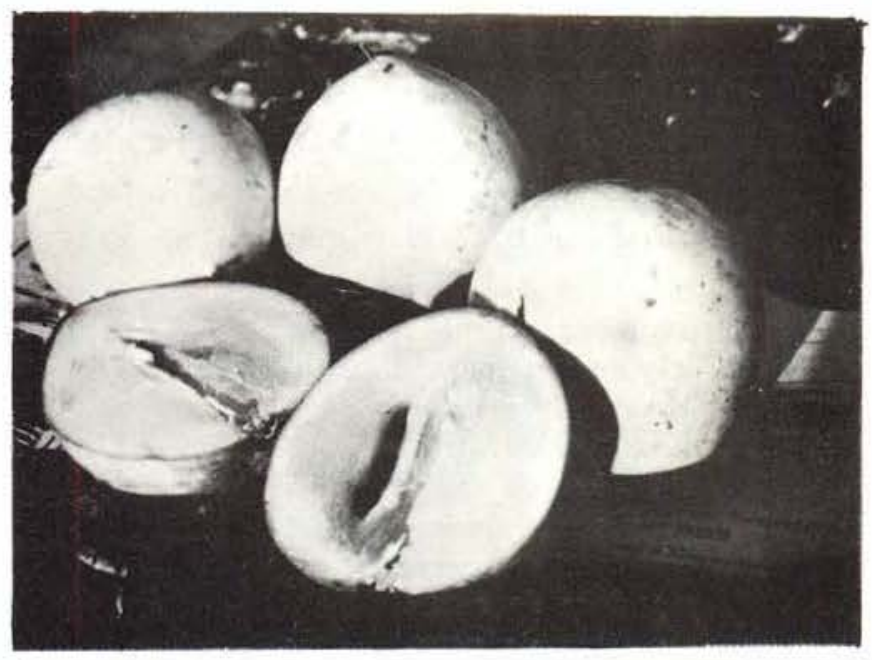

Fig. 1 - Abiu, de Benjamin Constant, AM, com 800 a 900 gramas de peso e apenas 1 ou 2 caroços.

os melhores cultivares, fruto dessa seleção. As melhores árvores que encontramos na Amazônia (Clement et al. 1978) tinham até 1.200 cachos (em 1977, foi um ano de grande produção) e algumas árvores tinham fruto de $3.2 \mathrm{~cm}$ de diâmetro (Fig. 2) . Começam a produzir em 3 anos. Em Letícia, há um pomar com 18 anos: de 20 pés, apenas 2 morreram nesse período.

Estamos divulgando esta espécie, não obstante sabermos ser ela atacada por brocas (vimos uma árvore em Letícia atacada por broca, coleóptero), fungos, gafanhotos, cigarrinhas, coccídeos (nas plantas da casa do Diretor em Manaus), dadas as suas possibilidades como substituta da uva nesta região.

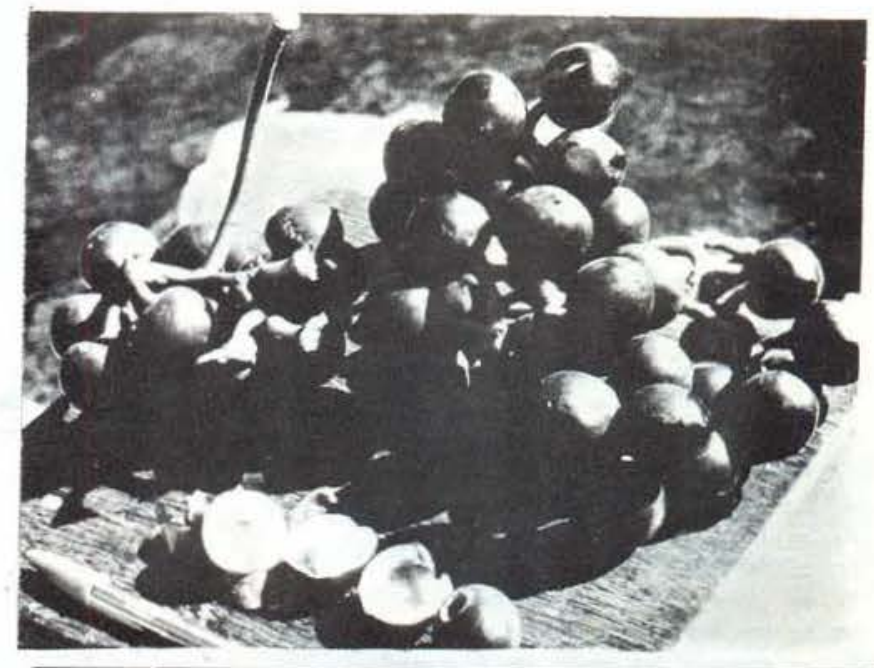

Fig. 2 - Mapati, colhido em Letícia, Colômbia. 
Sapota (Quararibea cordata (Humb. \& Bonpl.) Vischer, Bombacaceae. A planta selvagem produz frutos apenas com 9 a $12 \mathrm{~cm}$ de comprimento por $3-5 \mathrm{~cm}$ de diâmetro. As seleções dos índios Tikúna no Alto Solimões levaram a árvores que produzem de 3.000 a 8.000 frutos, quase esféricos, de 10 a $15 \mathrm{~cm}$ de diâmetro, pesando 400 a 1.300 gramas (Fig. 3). É de casca dura, de 7 a $13 \mathrm{~cm}$ de grossura, agüentando bem o transporte, o que a torna predestinada à exportação. A árvore da casa do Diretor do INPA (plantada em fevereiro de 1979) com 2 anos e meio, alcançou $2,20 \mathrm{~m}$ de altura; o seu broto ponteiro foi cortado - isso determinou o brotamento de 5 ramos laterais que estão com mais de um metro cada um (esta planta tem sido adubada). Esta espécie chega a produzir árvores com 30 metros, com folhas e formato semelhantes ao pau-balsa. É planta duradoura. Em Tefé, existiam pelo menos 3 sapoteiras com 80 a 100 anos. Dados o desinteresse, ignorância e ampliação das vilas, as sapoteiras foram cortadas a ponto de existirem menos de 500 árvores de sapoteiras selecionadas na Amazônia.

Esta planta também não se disseminou na Amazônia, o que pode ser devido a uma domesticação recente.

Sapoti, sapotilha (Manilkara zapota (L.) P. Van Royen Sapotaceae): É conhecida em toda a calha do Amazonas. Produz em árvores de grande porte (25 metros). Cơmeça a produzir em três anos, porém uma árvore plantada em

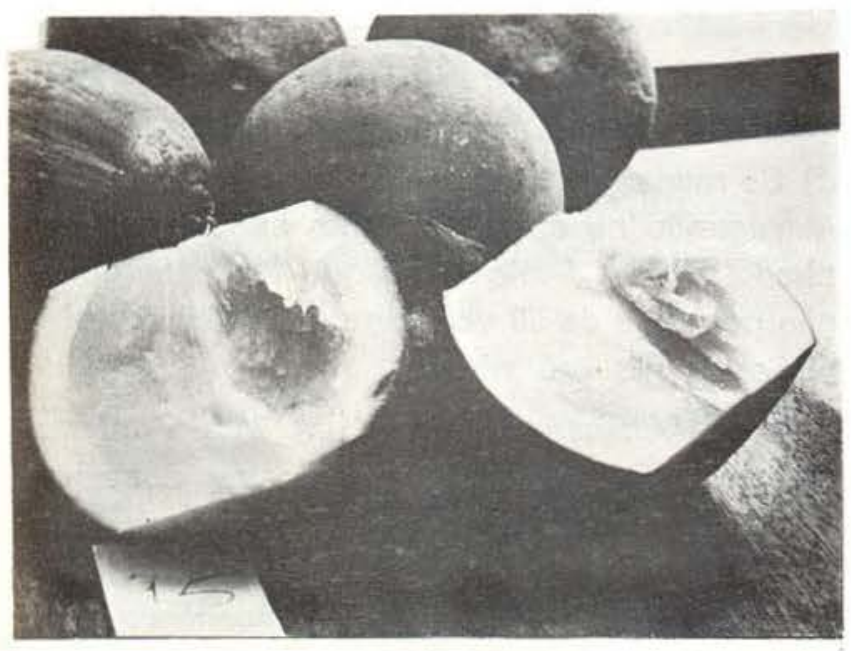

Fig. 3 - Sapotas, de Tefé, AM, com peso aproximado de 600 gramas.
Ribeirão Preto frutificou com 15 anos pela primeira vez. Existem na Amazônia tanto a variedade "sphaerica" (de frutos redondos) quanto a "depressa" (de frutos ovóides). Encontramos em Silves, AM, um grupo de árvores com frutos grandes, com uma a três sementes e passiveis de serem consumidos cerca de 10 dias antes da variedade comum, o que permitirá seu transporte a mercados consumidores mais distantes.

Pupunha (Bactris gasipaes HBK): É uma planta quase tão importante quanto a mandioca para os Yanomamö, Mayongong, Tukána, Tikúna, Desâna, Baníwa e, provavelmente, outras tribos sob suas influências. Não é de igual importância por produzir durante apenas 3-4 meses do ano, e a mandioca produz o ano todo.

A pupunheira (Galvão, 1959: 162) goza de tal preferência entre os Baníwa, que os caboclos da área a consideram como "palmeira sagrada" dos índios; antes mesmo da construção de uma casa, em aldeia nova, os índios plantam várias mudas de pupunheiras.

Experimentos do Dr. D. Arkcoil mostram que uma adubação adequada amplia o período de produção de frutos.

As seguintes informações são de Mora (com. pessoal) .

Em Quitchua significa: o fruto-das-aves. Tem $\mathrm{n}=14$ cromossomos. Há indicaçōes de Bactris gasipaes selvagem na Amazônia boliviana. A floraçăo dura 3 dias havendo por cacho cerca de 100 a 300 flores femininas e 20.000 masculinas. E especialmente fecundada pelo besourinho curculionídeo Derelomus palmarum no $1 i^{\circ}$ dia pela gravidade e pelo vento do $2:^{\circ}$ dia. Muitas plantas têm autoesterilidade genética (quantitativa). Em um experimento, uma árvore mostrou que $30 \%$ de seus frutos foram polinizados por outra situada a 30 metros. O fato de ter espinhos e a outra não ter espinhos é regido por um gene maior, porém se considerado em tamanho e número de espinho vê-se que é quantitativo.

Clement et al. (1978) deixam implícito que se precisa selecionar a pupunha (Fig. 4) visando-se a: a) várias variedades (pois os gostos diferem muito quanto à pupunha); b) estender a época de produção para ter-se pupunha todos os meses do ano; c) alta produção (cachos e tamanho); d) produzir 2 a 3 mudas por ano; e) sem espinhos; f) alta taxa de vitamina 


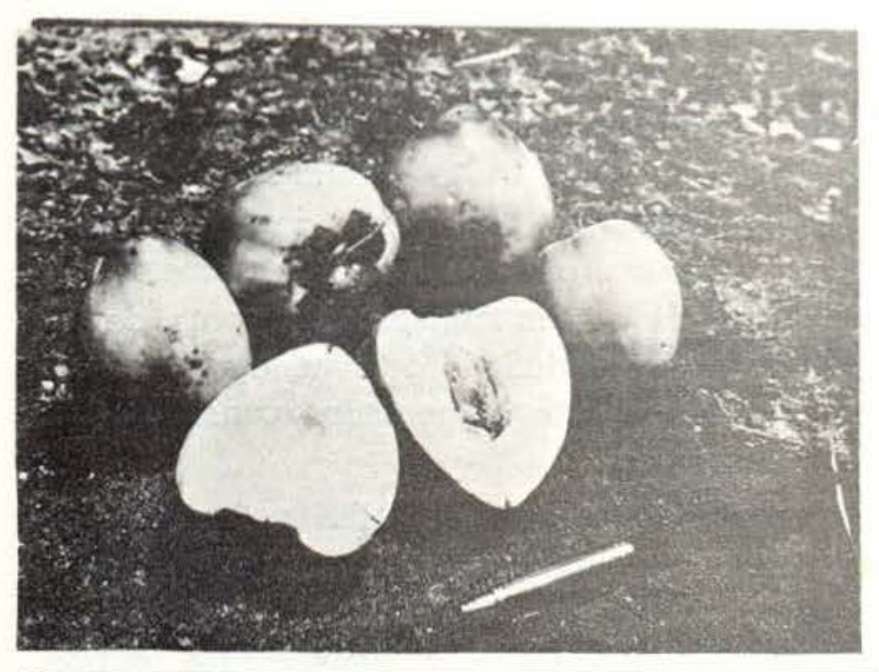

Fig. 4 - Pupunhas grandes, de Benjamin Constant, AM.

A, de proteína e de óleo comestível. Podemos acrescentar: g) sementes pequenas; h) parte comestível não fibrosa; i) produção a baixa altura; j) alto conteúdo de vitaminas $\mathrm{B}$ e $\mathrm{C} ; \mathrm{k}$ ) precocidade, I) fácil de ser descascado.

Vejamos agora quais os cuidados que os Desâna e Tikúna tomam para a seleção e plantio de sementes de pupunha:

\section{Desâna}

\section{(Informações do Chefe Tolaman)}

Para a seleção levam em conta os seguintes caracteres: $1^{\circ}$ ) número de cachos; $2 .^{\circ}$ ) tamanho dos frutos; $3^{\circ}$ ) devem ser eliminadas as plantas que produzem frutos com manchas ou rachas pretas, que secretam uma resina escura (parece breu) e que se estragam e cheiram mal.

No momento do plantio procedem assim: a) põem os frutos na água (numa vasilha); b) aquecem até mais ou menos $50^{\circ} \mathrm{C} ; \mathrm{c}$ ) ao atingir $50^{\circ} \mathrm{C}$ retiram as sementes de quantas queiram plantar; d) plantam; e) replantam no lugar definitivo quando têm um mínimo de $10 \mathrm{~cm}$ e um máximo de $60 \mathrm{~cm}$ de altura. Há várias crendices associadas ao cultivo da pupunha, entre os Desâna. As duas principais são: a) raspando a semente com um ralo, a planta não produzirá espinhos e b) se amarrar as folhas novas em cima, a árvore crescerá pouco e produzirá cachos a baixa altura.

\section{Tikúna}

Já entre os Tikúna as técnicas usadas na seleção e no plantio são: (Informação Sr. Camilo) :

a) Se desejar palmeiras sem espinho deve-se colher sementes de palmeiras sem espinho.

b) Se tiver a opção entre plantas com 2, 3, 4 cachos e 10,11, 16, deve-se escolher as com maior número de cachos. Isso porém não é um caráter absoluto porque eles sabem que a pupunheira produz mais após ter 4 a 5 anos de produção. Assim, se uma planta de 12 cachos apresentar frutos melhores que uma de 16. escolhe-se a primeira.

c) fruto grande é uma qualidade desejada.

d) Não coletar de plantas que produzem frutos que caem do cacho.

e) Não coletar de plantas que tenham frutos com doença, que apodrecem no cacho.

f) Alguns preferem seca; a maioria prefere oleosa.

\section{Crendices associadas:}

a) No momento do plantio, deve-se ter nas cos. tas um paneiro bem cheio, de modo a se fazer bastante esforço, - isso "fará" a pupunheira produzir muito. Se plantar descansado, sem esforço, a pupunheira não se "esforçará" também e produzirá pouco;

b) Plantando com casca de aruá (Pomatium amazonicum) a pupunheira dará cachos bem em baixo, sem isso dará no alto;

c) Se passar banha de tartaruga na semente as pupunhas sairão oleosas;

d) Se raspar a semente, lixá-la até ficar lisinha, esfregando na cinza, a planta sairá sem espinhos. O Sr. Camilo disse que fez essa operação por mais de 50 vezes e nunca deu certo! e, porisso, não crê nisso.

Abacaxi (Ananas comosus (L.) Merril, Bromoliaceae): $O$ fruto múltiplo (sorose) dessa espécie, em estado selvagem, é de apenas $12 \mathrm{~cm}$ de comprimento e pesa entre 100 a 200 gramas e suas folhas têm espinhos. Encontramos na Amazônia uma variação enorme entre tribos, com variedades: com espinho ou sem espinho; parte comestível amarelo-gema, amarelo-clara, 
branca; com coroa, sem coroa (esta, comum em Manaus, sem grande valor comercial, pois torna a fruta facilmente atacável por broca que penetra pelo tope); ácidos até muito doces; com muita bromelina, com pouca; de 800 gramas até 15 ou mais quilos (um exemplar de $21 \mathrm{~kg}$ de abacaxi de Tarauacá me foi mostrado no aeroporto de Rio Branco, que era presente do Dr. Geraldo Gurgel de Mesquita, Governador do Acre de 1974-1978, para uma autoridade em Brasília).

Os Desâna têm duas variedades de abacaxi: de arara e abacaxi de piraíba (este sem espinho). Comem no tucupi. Os Paumarí também têm duas variedades (Prance \& Kerr, 1976) .

Todas estas descrições acima, de frutas da Amazônia, e outras de banana (de que têm 10 a 15 cultivares), de cubiu (veja Pahien, 1978), caju, cupuaçu, ituá, parinari, etc., indicam a grande necessidade de desenvolver-se, em vários lugares uma fruticultura de primeira classe com prioridade em: coleta de material entre os índios, seleção e testes de variedades em múltiplas localidades, cruzamentos e biologia (veja mais dados em E. Pahlen (1978), Cavalcante (1977) e LeCointe (1947)).

\section{TUBEROSAS}

Os índios da Amazônia conseguiram selecionar um colosso de tuberosas das quais mantem vários cultivares. Daremos alguns exemplos dos Desâna :

a) Cará : (Dioscorea sp., Dioscoreaceae) : Existem 8 cultivares entre os Desâna, a saber :

- cará preto (ñamu-ñiri): roxo como batata roxa.

- cará de raiz comprida (nogõri-nhamu) .

- cará de japu (umu-nhamu): casca roxa.

- cará enrolado (berurí) .

- cará do diabo (uatí-inhamu) .

- cará de espinho (polá-inhamu): grande e produtivo.

- cará de fruto (dëkakëli-inhamu): é o que chamamos cará-de-árvore .

- cará camuti (peru-soró-inhamu).

Cará em Desâna é nhamu.

b) Batata-Doce: (Ipomoea batatas Lam. Convolvulaceae) .
Os Desâna possuem 4 cultivares :

- batata de pupunha (ënri-nhapi): amarela como pupunha.

- batata de mandioca (quí-nhapi): branca.

- batata de cuia (coá-nhapi): roxa

- batata preta (nhapi-nhiri): preta.

Os Paumarí possuem 3 cultivares.

c) Taioba : (Xanthosoma sp. Araceae): É uma variedade que produz uma batata muito grande, por isso chamam "batata do povo" (maçã kábô) .

d) Ariá: (Calathea allouia, (Aubl.) Lindl. Marantaceae): Os Desâna tem dois cultivares: um que produz tubérculos compriáos, como urna cenoura, e outra que os produz parecidos com batatinha redonda. Martin e Cabanillas (1976) informaram que o ariá tem $66 \%$ de proteína e 13 a $15 \%$ de amido (peso seco). sendo que a proteína é rica em metionina e ácido glutâmico e deficiente em cistina.

e) Caroço-de-umari: (Calathea sp.): (em Desâna: maiarê). Parece ariá, porém não é raiz — é rizoma, isto é, brota.

CUPÁ, UVA-DO-MATO, CIPÓ-BABÃo (Cissus gongylodes Burch. ex-Baker, Vitaceae).

O cupá é um cipó, da família Vitaceae, que deve ter sido domesticado há pouco tempo (no máximo 1000 anos) pois é plantado, consumido e transformado em farinha, por poucas tribos (Kayapó, Apinayé, Xerénte, Timbíra, Gavião) . A variedade selvagem é fina (diâmetro $1 \mathrm{~cm}$ no máximo) e a melhorada pelos índios chega a ter $4 \mathrm{~cm}$. É uma verdadeira mandioca arbórea (mais detalhes em Kerr et al., 1978); é plan'tada por manivas (como no plantio da mandioca). Os índios Kayapó as plantam verticalmente enterrando $20 \mathrm{~cm}$ deixando outro tanto para fora, usualmente encostado ao tronco de uma árvore. Sobe nas árvores a grandes alturas. Cresce em solos pobres. As manivas são comidas pelos Kayapó tanto assadas como cozidas. Tem gosto de macaxeira porém não contém $\mathrm{HCN}$. Tem $35 \%$ de casca e $65 \%$ de âmago (a parte comestível). A umidade do âmago é $73 \%$ a $77 \% ; 1,2 \%$ proteína; $18 \%$ de carbohidratos, $1 \%$ de gordura (Kerr et al., 1978). 
PosSível AUTODOMESTICAÇÃo

DO PATO SELVAGEM AMAZÔNICO

\section{(Cairina moschata, L., Anatidae) .}

O único animal encontrado domesticado pelos índios amazônicos foi o pato brasileiro.

Os índios tinham uma grande quantidade de caça e pesca ao seu redor. Porisso, não tiveram necessidade de recorrer à domesticação de animais.

Os indios gostam dos animais e tratam bem os filhotes que aprisionam. Vários animais (mamíferos e aves) rodeiam as vilas e aldeias à procura de restos de alimento. Neste caso estão os patos. Duas mutações - uma que fez os patos dormirem no chão, não usando árvores como poleiros e, outra, que os tornou mais dóceis, não fugindo tão rapidamente, como fazem os selvagens, foram importantes na domesticação.

Com apenas essas duas mutações, os patos se tornaram domésticos e com isso aproveitavam-se de mais uma fonte de alimento. Logo, é possível que o único animal encontrado domesticado entre os índios, na realidade, se tenha autodomesticado, por esses dois genes os habilitarem a ocupar um nicho ecológico vazio (de patos!).

\section{CONCLUSÃo}

Os índios sul-americanos domesticaram um grande número de plantas comestíveis nos últimos 10 a 20 mil anos de ocupação deste continente. Este trabalho indica a mandioca como uma das mais antigas, somente ultrapassada pelo milho, em virtude de ter ocupado ampla área geográfica, ser posse de grande número de tribos e ter um grande número de cultivares (mais de 200), 20 em média por tribo, chegando nos Desâna e Tukâna a 40 cultivares. Outras tuberosas importantes são: cará ( 8 cultivares), batata-doce (4 cultivares), e ariá (2 cultivares). Das fruteiras, o maior destaque é para a pupunheira. Sugere-se que uma das mais recentes domesticações seja o cupá.

As seleções feitas pelos índios em tuberosas, cereais e fruteiras foram baseadas em práticas e crenças que tiveram como conse- qüência genética a produção de dezenas de espécies com um total de cerca de 400 cultivares.

Já estivemos (W. E. Kerr) em quase 30 tribos de índios. Em nenhuma, passamos fome. Porém, é evidente que nas tribos próximas às cidades, ou em contato com os brancos, está havendo uma diminuição tanto na diversidade como na quantidade de alimentos, às vezes pequena e às vezes drástica, por estar sendo perturbada a maneira de os adultos passarem os conhecimentos aos jovens, de uma geração para outra. Tal fato é agravado pela presença de padres e pastores. Estes, destruindo os mitos e superstições (que vão tentar substituir por ensinos cristãos) tornam os índios, que aceitam essa troca, receosos de transmitir seus conhecimentos da mata por estarem, tais conhecimentos, misturados com suas crenças.

Porisso, é prioritário um trabalho integrado dos pesquisadores de Agricultura, de Medicina, de Ecologia e de Botânica do INPA e outros órgãos de pesquisa para aproveitarem ao máximo o conhecimento, as práticas e as sementes dos índios amazônicos e ao mesmo tempo contribuirem para uma instrução etnobotânica aos pastores e padres, que os auxiliem a enxergar os índios como ótimos professores de betânica, de agronomia e da ecologia amazônica, e incentivem a passar seus conhecimentos aos jovens, inclusive contratando-os como professores das escolas.

\section{AGRADECIMENTIOS}

Agradecemos as informações dadas pelos amigos índios Saba (Yamamadí, do médio Purus), Tolaman Ken-hiri (Chefe dos Desâna) e Camilo Mestança (ancião dos Tikúna); e ao $\mathrm{Sr}$. José Ferreira da Silva por criar os "meus patos !"

\section{SUMMARY}

Cultivars of food plants actually found in Amazonia that are different from present days wild varieties have been selected by the indians in the last 10,000 years in South America and likely in the last 4,000 to 1,000 years by Amazonian tribes. This paper analyses 40 cultivars of manhioc of Desana and 13 of Tikuna. 
Surveys in 7 indian tribes reveal an average of 22 cultivars per tribe. Discussed are wild and selected (by the indians) "varieties" of several fruit trees: abiu Pouteria caimito), sapota (Mlatisia cordata), sapoti (Manilkara zapota), pupunha (Bactris gasipaes), pineapple (Ananas exculenta). Attention is given to some domesticated tuber plants (yam, sweet-potatoes, taro, leren) and to cupá (Cissus gongilodes); this last one, due to the small distribution may be one of the most recent domestications. It is suggested that the duck (Cairina moschata) domesticated itself in order to occupy the empty niche near the tribes.

\section{BIBLIOGRAFIA}

Carvajal, gaspar de; Royas, Alonzo de \& Acuña, CRISTOBAL DE - I

1543 - Descobrimentos do Rio das Amazonas Reed. São Paulo, Companhia Editora Nacional. 1941. Cap. 24.

Cavalcante, paulo B.

1976 - Frutas Comestíveis da Amazônia. 3 ed. INPA, Manaus, 1976

Clement, Charles R.; Kerr, Warwick Estevam; Weber, Heroldo; Freitas Jr,, Elias de; Arkcoll, David, B.; Ranzani, Guido \& Pahlen, Eva von der

1978 - Ecologia e Fruticultura na Amazônia. IN: ${ }^{\circ}$ Encontro Brasileiro de Fruticultura Tropical (no prelo).

GALVÃo, EdUARDO

1959 - Aculturação indígena no Rio Negro, Bol. Paraense E. Goeldi, Antrop., 7: 1-60.

Giugliano, Rodolfo; SHRimpton, Roger; ARKCOll,

David B.; Giugliano, Loreny G. \& Petrere Jr., Miguel

1978 - Diagnóstico da realidade alimentar e nutricional do Estado do Amazonas. 1978. Acta Amazonica, 8(2) Suplemento 2: 1-54.

GOOdMAN, M.M. \& SMITH, J.S.C.

1978 - Botânica. IN: "Melhoramento e produção de milho no Brasil". Paterniani, E. ed. Marprint, Piracicaba, Brasil. p. 32-70.

JENNINGS, D.L.

1976 - Cassava. IN: Simmond, N.W. ed. Evolution of crop plants. New York, Longman. 1946. p. 81-84.

KERR, W.E.

1978 - Papel das abelhas sociais na Amazônia. IN: Anais do Simpósio Internacional da Apimondia sobre "Apicultura de Clima Quen. te". (Florianópolis, 20-10-78). Bucareste. Editora Apimondia, p. 119-129.

KerR, W.E.; POSEY, DARRELl A. \& Wolter, Wilson 1978 - Cupá ou Cipó-babão, alimento de alguns indios amazônicos. Acta Amazonica, 8 (4): $702-705$.
Le CoInte, Paul

1947 - Árvores e plantas úteis do Brasil. 2n ed Companhia Editora Nacional. Brasiliana. V. 251. 500p.

Maravalhas, N.

1964 - Cinco estudos sobre a farinha de mandioca. Publicação do INPA. Série Química, (6): $1-21$

Marinho, H.A.; Shrimpton, R. \& ARkColl, D.B.

1978 -.. Yellow cassava flower as a rich source of vitamin A. IN: Abstracts XI Lut. Congress Nutrition, (30): 29

Martin, Franklin \& Cabanillas, Eugenio

1976 - Leren (Calathea allouia), a little known tuberous root crop of Caribbean. Economic Botany, 30: 249-256.

PAHLEN, Alejo VON DER

1978 - Cubiu (Solanum topiro Humb. \& Bonpl.), uma fruteira da Amazônia. IN: "Introdução à Horticultura e Fruticultura no Amazonas". Manaus. Edição da SUFRAMA

PAHLEN, EVA VON DER

1978 - Fruteiras para o Amazonas. IN: "Introdu. ção à Horticultura e Fruticultura no Amazonas". Manaus. Ediçấo da SUFRAMA

PRANCE, G. T. \& KeRR, W.E.

1976 - Ciência, aventura e Fé. Excursão do INPA ao Rio Purus. "O Estado de São Paulo", Suplemente Centenário, p. 5 e 6, 24-01-76.

RIBEIRO, DARCY

1955 - Os indios Urubus. Ciclo anual das atividades de subsistência de uma tribo da Floresta Tropical. IN: XXXI Congresso Int de Americanistas, p. 127-155.

SHRIMPton, R. \& GIUGliANo, R.

1979 - Consumo de alimentos e alguns nutrientes em Manaus, Amazonas, 73-74. Acta Amazonica, 9 (1): 117-141.

SIMÕ̃es, MárIo F.

1972 - Indice das fases arqueológicas brasileiras. 1950-1971. Publ. Avulsas Museu Paraense Emilio Goeldi, Belém (18).

TÉLlEz, G. MEDINA

1979 - ARARA, the capital of the Ticuna indians of the Colombian Amazon. New York. Exposition Press. p. 22.

WHITAKER, THOMAS W.

1976 - Cucurbits. IN: Simonds, N.Y., ed. "Evo lution of crop plants". New York, Longman. p. $64-69$

Zevallos, Carlos M.; Walton, C.G.; Donald, W.L.; Leng, Earl K.; Marcos, J.G.; \& Kathleen, M.K.

1977 - The San Pablo Corn Kernel and its Friends. Science, 196 (4288): 385-389.

(Aceito para publicação em 07/02/80) 